\section{Prevalence and environmental impact factors of somatization tendencies in eastern Chinese adolescents: a multicenter observational study}

\section{Prevalência e fatores ambientais de tendências de somatização em adolescentes do leste chinês: um estudo observacional multicêntrico}

\author{
Prevalencia y factores de impacto ambientales \\ en las tendencias somatización con adolescentes \\ de la China oriental: un estudio observacional \\ multicéntrico
}

\author{
Qinglin Cheng 1 \\ Yong $\mathrm{Xu} 2$ \\ Li Xie 1 \\ Yunkai $\mathrm{Hu} 3$ \\ Yongxiang $L v 4$
}

doi: 10.1590/0102-311X00008418

\begin{abstract}
The aim of this study is at examining the prevalence and impact factors of adolescent somatization tendencies (ST) across three eastern Chinese provinces. A multicenter school-based cross-sectional study was conducted in these provinces from 2015 to 2016. The sample included 11,153 middle-school students aged 13-18 years, who were randomly selected using a multi-phase stratified cluster sampling technique. We also designed a multicenter schoolbased case-control study to evaluate the potential environmental impact of ST factors on this population. The overall positive rate of ST among the eastern Chinese adolescents was 12.1\%. Somatic symptoms score (SSS) and positive $S T$ rate were higher in females than males. Additionally, the SSS and positive ST rate for the 18-year-old group were significantly higher than in other age groups. In comparison to those in urban areas, adolescents in rural areas had significantly higher SSS and positive ST rate. Multiple conditional regression analyses revealed that family medical history, anxiety and depression scores; superstitious beliefs; left-behind adolescents; teacher-student support; family conflict; and family independence and achievement orientation were significantly linked to ST in adolescents. The models also indicated family medical history was the strongest impact factor to adolescent ST, even though ST were prevalent in the three studied eastern Chinese provinces. Gender, age, and dwelling differences were very significant in the SSS and positive ST rate in adolescents. This study concludes that adolescent ST are influenced by multiple environments.
\end{abstract}

Somatization Disorders; Adolescent; Prevalence; Multicenter Study

\author{
Correspondence \\ Y.Xu \\ School of Public Health, Medical College of Soochow University. \\ No 199, Ren'ai Road, Suzhou 0512, China. \\ xuyongszdx@sina.com \\ 1 Hangzhou Center for Disease Control and Prevention, \\ Hangzhou, China. \\ 2 School of Public Health, Medical College of Soochow \\ University, Suzhou, China. \\ 3 Fuyang Center for Disease Control and Prevention, Fuyang, \\ China. \\ 4 Jin'an District Center for Disease Control and Prevention, \\ Lu'an, China.
}




\section{Introduction}

As originally described in the 3rd edition of the Diagnostic and Statistical Manual of Mental Disorders (DSM-III), the somatization disorder (SD) is characterized by a wide variety of somatic symptoms affecting different organ systems. Previous studies define SD as the psychological mechanism whereby psychological distress is expressed in the form of physical symptoms. The most common of these symptoms are abdominal, back, and chest pain; dyspnea; headache; fatigue; cough; nervousness; and dizziness 1,2 .

The SD, characterized by complaints of unexplained physical symptoms, is commonly present in children and adolescents in both primary and secondary care settings. This disorder significantly impacts children, as well as healthcare resources: such as in adults, there is a wide range of severity and handicaps resulting from $\mathrm{SD}^{3}$. In recent decades, there has been a growing awareness of SD in childhood and adolescence in the world, with plentiful evidence explaining the high prevalence of SD in the adolescent population 3,4. More specifically, a general teenage population (aged 12-16 years) survey found that SD was present in $11 \%$ of girls and $4 \%$ of boys 5 . However, in studies from some European countries, the reported prevalence of SD ranged from $0.1 \%$ to $0.8 \%$ in the general Western population 6,7. Furthermore, epidemiological studies of adolescents aged 13-18 years conducted in Oman and the Philippines found higher prevalence rates of SD compared with Western countries 8.

In a literature review, we also found that younger females from specific ethnocultural groups, with certain family medical histories or who have endured childhood sexual abuse, substance abuse, anxiety and depressive disorders or traumatic events are at an increased risk for adolescent SD 3,4. Another study demonstrates SD has a major impact on the functioning and quality of life and can often affect anyone in early life for sustained periods, thereby leading to many years of disease 9 . Costello et al. 10 assert that SD may result in significant social, economic, and health burdens in children and adolescents. As such, to reduce future SD cases, exploring potential SD impact factors - including modifiable ones -, is necessary.

Some studies suggest that young people show early signs before the onset of SD, such as somatization tendencies (ST) 8,11. A study by Zhou et al. 12 explains that STs are the tendency to experience and communicate psychologic distress in the form of somatic symptoms - that is, in a somatic tendency mode -, widespread in both our own as in other cultures. As such, STs are not in any sense pathological nor constitutes a medical or psychiatric problem. Some of them are entirely subjective and may represent bodily metaphors with which the patient expresses emotional distresses or conflicts. What patients subjectively perceive as pain or some other somatic discomfort represents the experiential aspect 11 . Other studies indicate that STs put individuals at risk for several adverse outcomes, including furthered SD, chronic pain, long-term sequelae, and a range of other mental health problems such as suicide, anxiety, and depression disorders 8,13,14. Several prior studies report that Korean depressives manifest more STs and fewer feelings of guilt and suicidal ideation when compared with Western patients 12,15 .

The links between STs and adverse outcomes are thought to reflect early signs of SD overtime. Even so, there is little information about such association. For example, although the links between STs and adverse outcomes have been well documented 13,14,15, no specific prevalence or risk estimates pertaining to adolescent STs are available. Additionally, there is scant research containing empirical investigations of environmental impact factors causing STs. The theoretical work concerning the ST pathological mechanisms is also scarce. In a stark contrast, SD risk factors have been extensively researched. To effectively decrease the risk and prevalence of adolescent SD, we investigated potential ST impact factors using large-scale epidemiological studies to develop effective interventions against STs.

The purpose of this study is to estimate the prevalence of STs in adolescents. In particular, we are interested in evaluating environmental impact factors associated with STs across three eastern Chinese provinces. For this purpose, we designed a multicenter cross-sectional study to discuss the prevalence of STs in adolescent. In addition, we conducted a multicenter case-control study to ascertain the ST environmental impact factors in this population. 


\section{Subjects and methods}

\section{Sample size calculation}

To calculate sample size, we used the following formula 16 :

$$
n=\frac{Z^{2} \times P(1-P)}{d^{2}} \times d e f f
$$

Where $n$ = sample size; $Z=Z$ statistic for confidence level; $P=$ expected prevalence or proportion (in proportion of 1 ; if $50 \%$, p-value $=0.50$ ); and $d=$ precision (in proportion of 1 ; if $2 \%, d=0.02$ ). Multistage sampling methods require a larger sample size to achieve the same precision; therefore, the sample size calculated using the formula above was multiplied by the design effect deff.

$Z$ statistic $(Z) 16$ : for a $95 \%$ confidence level, which is conventional, the $Z$-value is 1.96 . In this study, the investigators present their results with $95 \%$ confidence intervals $(95 \% \mathrm{CI})$ and $\operatorname{deff}=3$. In addition, considering the loss to follow-up (referring to students who were lost in the follow-up survey), student rejection rate, sampling error, and stratification factors, the final sample size was determined to be 12,960 .

\section{Study methods}

This research was a multicenter school-based, cross-sectional study. The schools were selected using a random number table and a stratified cluster sampling method, from three School Health Surveillance System (SHSS) centers from three provinces (Anhui, Jiangsu, and Zhejiang) in China; in total, 24 schools were recruited. A sample of 540 students aged 13-18 years was randomly selected at each of the enrolled schools using a random number table and a stratified sampling method. For inclusion, adolescents had to be mainstream students (i.e. have no intellectual disability), aged 13-18 years, and able to converse in Chinese. They were excluded in cases of a reported history of psychosis or neurocognitive deficits, or if they received a secondary mental health service. Further details are available in Figure 1.

In this study, adolescent STs were assessed in a two-stage appraisal procedure. In the first stage, STs were screened by the somatic subscale of the Brief Symptom Inventory (BSI) 13,17. In the second stage, individuals whose responses to the BSI suggested they might have STs were further assessed by three psychiatrists to obtain a final diagnosis. About 60 trained fieldworkers administered 2 questionnaires to subjects who were assessed as presenting STs; face-to-face assessments and investigations were conducted in each of the 3 SHSS centers by the fieldworkers. In addition, 6 trained fieldworkers were present in each of these centers to control the quality of the research process.

We also designed a school-based collaborative case-control study, in which each center used a common protocol and core questionnaire. For each ST case, 2 control individuals matching in age, gender, and residence area were randomly selected from the 3 SHSS centers using a random number table method. Then, 3 or 4 control individuals were randomly selected to compensate for non-response and to ensure balance in the number of cases and control individuals at each center. For consideration, the control individuals had to be mainstream students (i.e. had no intellectual disability or history of psychosis/neurocognitive deficits); have a somatic symptoms score (SSS) < 10; be from the same area and of the same sex and age as the corresponding student in the case group; and be mentally healthy. To ensure the consistency of inclusion and exclusion criteria, all control individuals were assessed by a psychiatrist. Trained fieldworkers evaluated the potential ST impact factors in case and control students using standardized assessment instruments, including the Family Environment Scale (FES), the Chinese Adaptation Scale for Adolescents (CASA), the Student-Teacher Relationship Scale (STRS), the Chinese version of the Peer Relationship Inventory (CPRI), and the Hospital Anxiety and Depression Scale (HADS). 
Figure 1

Data sampling flowchart.

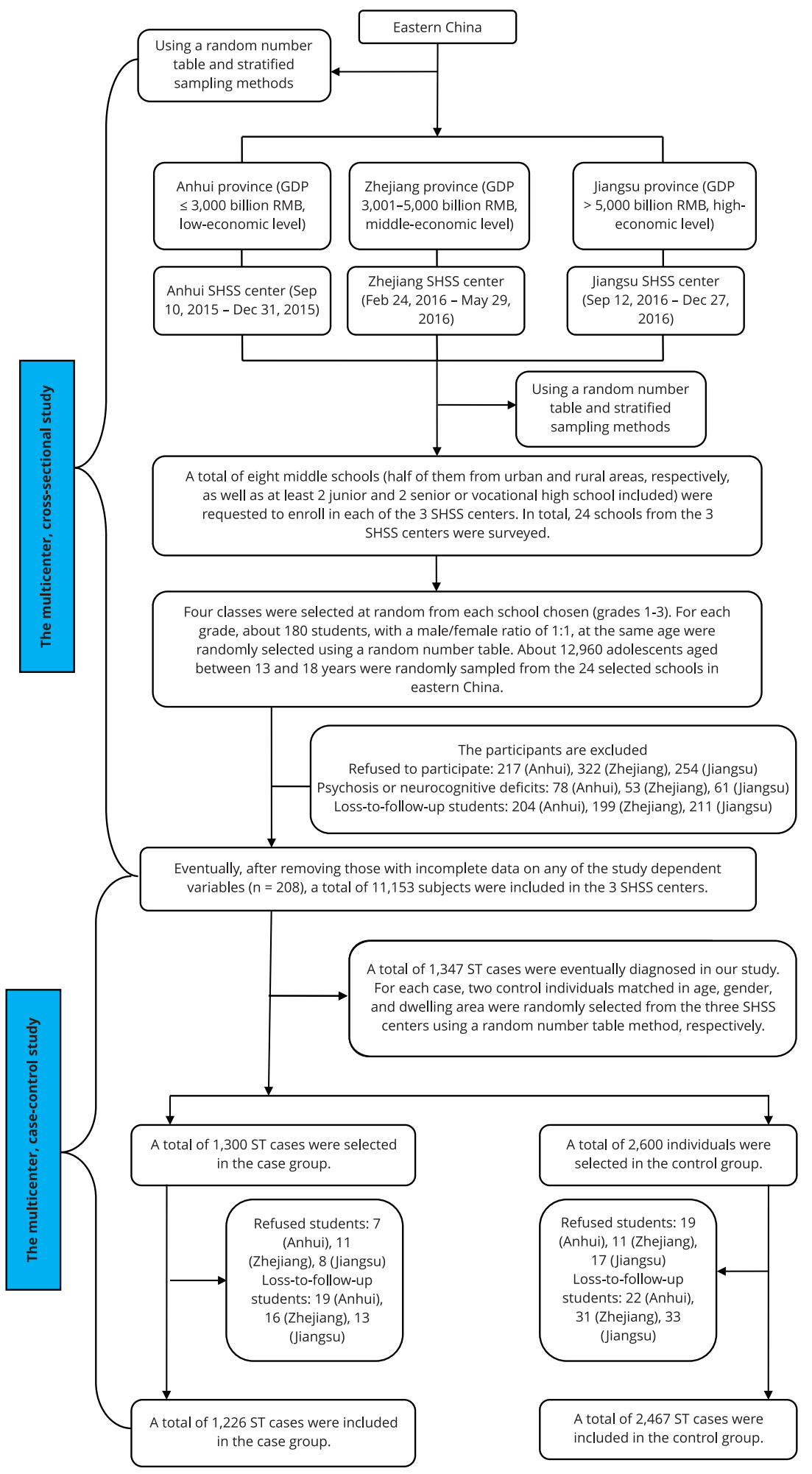

GDP: gross domestic product; SHSS: School Health Surveillance System; ST: somatization tendencies. 


\section{Measures and procedure}

\section{- Adolescent ST measurement}

This study featured a two-stage appraisal procedure to identify adolescent STs. In the first stage, the STs were screened with the BSI somatic subscale 17 , which involved questions about the distress caused by faintness or dizziness, pain in the heart or chest, nausea or upset stomach, trouble breathing, hot or cold spells, numbness or tingling in parts of the body, and weakness in parts of the body within 7 days before the screening. The BSI is a broadly applied self-reporting somatic symptoms scale discussed by Likert as five-point counts 18 , where each symptom was scored $0-4$, depending on the distress it caused, yielding a total score of 0-28. The SSS were low (0-9), medium (10-19), and high (20-28) 17. Sample's internal consistency was 0.84 (Cronbach's alpha).

Individuals whose responses to the BSI suggested they might have STs (i.e. a medium or high SSS $[\geq 10]$ ) were further assessed by three psychiatrists (including two chief physicians and a senior attending doctor) to obtain a final diagnosis, as follows. First, aimed at improving the diagnostic consistency and accuracy of the three psychiatrists, they carefully reviewed the SD diagnostic criteria, as well as related studies on STs. Next, the psychiatrists excluded all patients with SD and other mental or personality disorders using the DSM and the Chinese classification of mental disorders. Then, they independently estimated STs in participants using a semi-structured questionnaire including demographic characteristics and somatization personality (SP) traits 19,20,21. To ensure the consistency of the different psychiatrists' assessments, they utilized a mutual evaluation form; therefore, adolescent STs were only confirmed when consistently diagnosed by all three psychiatrists.

During such evaluation, the psychiatrists were primarily responsible for the ST diagnosis and differential diagnosis. The STs were noted if a subject had (a) a medium or high SSS ( $\geq 10$ ); (b) SP traits (i.e. neuroticism, vulnerability to stress, and histrionic behavior) 19,20,21; (c) precluding organic diseases, $\mathrm{SD}$, or other mental or personality disorders; (d) no history of psychosis or neurocognitive deficits; and (e) intact intellectual functioning (i.e. an intelligence quotient [IQ] > 70).

\section{- ST independently estimated by psychiatrists}

A semi-structured questionnaire with 45 self-reported items (including demographic characteristics and SP traits) was designed to assess the participants' STs. The questionnaire reliability was tested on 72 individuals in Suzhou, Jiangsu, whose STs are not included in this study. Responses were analyzed using Cronbach's alpha, and the results revealed an internal consistency of 0.84 regarding demographic characteristics and of 0.81 in terms of SP traits, suggesting the validity of the designed questionnaire.

\section{- IQ measurement}

To assess the participants' IQs, we administered the Chinese revision of the Wechsler Adult Intelligence Scale for adolescents aged 17-18 years and of the Wechsler Intelligence Scale for Children for adolescents aged 13-16 years 22 . The IQ tests were age-standardized with a mean of 100 and a standard deviation of 15 in the general population 23 . Adolescents were individually assessed under the same standardized laboratory conditions, at all ages. In this study, intact intellectual functioning was assessed on a full scale. The fieldworkers were trained with a uniform standard, and all tests were scored by two independent testers.

\section{- Demographic characteristics measurement}

A questionnaire was designed for assessing the demographic factors that contribute to STs. Such questionnaire included three main aspects: individual characteristics (gender, age, left-behind adolescents, and somatotype [referring to the overall outlook of the body to convey the totality of morphological features]), family factors (family income, family size, and superstitious beliefs [ranging from psychic powers to beliefs that are not attributable to scientific or religious explanations, such as supernatural, 
paranormal, or otherwise magical beliefs]), family medical history (i.e. a history of psychosis or neurocognitive diseases), and school characteristics (boarding school, administration model, and class size).

\section{- Social adjustment status measurement}

The CASA is comprised of three factors: emotional adaptation (6 items), social adaptation (6 items), and study and life adaptation (5 items) 24 . Related research suggests the CASA has high reliability and validity, with a 0.80 Cronbach's alpha 24,25 ; hence, it was used as an effective tool to assess adolescents' adaptation to social life. The adolescent adaptation was discussed using a four-point Likert scale for a total score of 17-68 points. In this sample, the internal consistency was 0.88 .

\section{- School environment status measurement}

Teacher-student relationship: the STRS is a 28 -item self-report instrument designed to measure a teacher's perception of their relationship with a given student 26 . The Chinese version of the STRS (STRS-CV) is a version of the scale translated and revised by Qu 27, based on Pianta's STRS 28. It includes four domains: intimacy, conflict, support, and satisfaction. Good internal consistency and acceptable test-retest reliability (with Cronbach's alpha of 0.71-0.87) were assessed in the related research 27 . The teacher-student relationship was tested using a five-point Likert scale for a total score of 23-115 points. In this study, the internal consistency was 0.87 .

Peer relationship: the CPRI is a 20-item self-report instrument designed to assess an adolescent's peer relationship. The CPRI was revised by Wei et al. 28 based on the 13-item Missouri Peer Relations Inventory 29 , and measures three analytically derived dimensions of peer relations: social maturity, aggression, and independence. The scale has high reliability and validity (with Cronbach's alpha of 0.58-0.86) 28. Peer relationship was analyzed using a five-point Likert scale for a total score of 20-100 points. In this sample, the internal consistency was 0.86 .

\section{- $\quad$ FES measurement}

The FES is a 90-item self-report instrument used to measure relationships, personal growth, and system maintenance in the context of one's family environment ${ }^{30}$. The Chinese version of the FES (FESCV) was amended by Phillips et al. 30 . Previous studies found that 10 subscales of the FES-CV demonstrate moderate to excellent internal consistency (ranging from 0.63-0.75) and acceptable test-retest reliability $(0.55-0.92) 31$. The internal consistency of this instrument was 0.85 .

\section{- Assessment of anxiety and depression}

Anxiety and depression were evaluated using the HADS, which was specifically developed to detect anxiety and depression in patients with somatic conditions 32 . The HADS is divided into an anxiety subscale (HADS-A) and a depression subscale (HADS-D), both of which containing seven items scored $0-3$, leading to a possible maximum score of 21 . Scores $<8$ indicate no clinical distress, scores 8-10 point out possible psychiatric morbidity, and scores $\geq 11$ suggest probable pathologic levels of distress 32 . Good internal consistency and acceptable reliability were demonstrated for the Chinese version of the HADS (with Cronbach's alphas of 0.81 for anxiety and 0.83 for depression) 31 . In this sample, the internal consistency was 0.84 .

\section{Statistical analysis}

All data were entered twice, verified, and de-identified in the EpiData open-source database, version 3.1 (http://www.epidata.dk/). Data were analyzed using R version 3.4.2 (http://www.r-project.org). Missing data imputation was conducted separately for each center, leading to three imputed datasets.

We used descriptive statistics to calculate the frequencies and percentages of the categorical variables as well as the mean \pm standard deviation of the normally distributed continuous variables. 
The matched odds ratio ( $\mathrm{mOR}$ ), the adjusted mOR (amOR), and a 95\%CI were used to measure the associations between impact factors and adolescent STs.

Univariate analyses were used to separately select all the covariates that were potentially associated with STs, to enter them into multiple regression models at a 0.05 significance level. We used three different analysis methods depending on the number and variety of variables: Independent t-tests were used for continuous variables with a normal distribution; Bartlett's one-factor variance test was used for three or more variables with a normal distribution and variance homogeneity; Pearson's chisquare test was used for categorical independent variables and to identify equilibrium between case and control students.

A conditional multiple logistic regression model was used to evaluate whether the covariates were associated with STs. A subsequent procedure was used to further select the covariates that were associated with ST at a significance level of $\mathrm{p}>0.05$, for removal, and a significance level of $\mathrm{p}<0.05$, for reentry. The final model was selected according to the minimum statistics of the Akaike information criterion. Hypothesis testing was conducted using a two-sided test with an alpha value of 0.05 to indicate statistical significance.

\section{Results}

\section{Baseline subject characteristics}

Refusal and loss-to-follow-up rates were $7.7 \%(994 / 12,960)$ and $4.7 \%(605 / 12,960)$, respectively, in the cross-sectional study. Overall, 11,361 questionnaires were completed at 24 schools. After removing questionnaires with incomplete data in any of the study's dependent variables ( $\mathrm{n}=208$, accounting for 1.8\%), 11,153 participants were retained for subsequent analyses.

The overall positive ST rate among the eastern Chinese adolescents was 12.1\% (95\%CI: 11.5-12.7) at $13.8 \%$ (95\%CI: 12.9-14.8) for females, and 10.3\% (95\%CI: 9.5-11.1) for males. The SSS $(\mathrm{t}=6.37$, $\mathrm{p}<0.001)$ and positive ST rate (chi-square $=33.21, \mathrm{p}<0.001)$ in females were higher than in males. Remarkably, when comparing adolescents aged 13-18 years, the SSS and positive ST rate for the 18 -year-old group were significantly higher than in other age groups $(\mathrm{F}=32.84, \mathrm{p}<0.001$; chi-square $=$ $16.51, \mathrm{p}=0.006$, respectively). In junior high school students (aged 13-15 years), grade 3 (aged 15 years) students' SSS was higher than grade 1 or grade 2 students $(F=24.03, p<0.001)$. Adolescents from rural areas had significantly higher SSS $(\mathrm{t}=13.91, \mathrm{p}<0.001)$ and positive ST rates (chi-square $=$ $7.78, \mathrm{p}=0.005)$ compared with adolescents from urban areas. The remaining two baseline characteristics, including nationality and sampling area, did not significantly relate to the SSS or positive ST rate in adolescents $(\mathrm{p}>0.05)$ (Table 1$)$

\section{Association between environmental impact factors and STs in eastern Chinese adolescents}

We enrolled a total of 1,226 ST cases and 2,467 control individuals in our multicenter, case-control study. Refusal and loss-to-follow-up rates were $2 \%(26 / 1,300)$ and $3.7 \%(48 / 1,300)$ in the case group, and $1.8 \%(47 / 2,600)$ and $3.3 \%(86 / 2,600)$ in the control group, respectively. Case and control subjects were matched by age, gender, and residence area (1:2). Statistical differences in baseline characteristics, including age, gender, and nationality, were not found in the multicenter case-control study ( $\mathrm{p}>$ 0.05). Therefore, this study was balanced.

Tables 2 and 3 summarize results of univariate analyses of the association between potential covariates and STs. About 21 of the 37 covariates tested were significantly associated with STs (p < 0.05), being the most significant: (a) demographic characteristics including family income, left-behind adolescents, family medical history, and superstitious beliefs; (b) social adjustment characteristics in terms of emotional adaptation; (c) teacher-student relationships, including intimacy, support, and conflict; (d) peer relationships for social emotion; e) family environment characteristics, including cohesion, conflict, and independence; and (f) psychological factors according to the HADS-A and HADS-D scores. The remaining 16 covariates (including parent education levels and occupations, environmental pollution, class staff, number of family members, social adaptation, study and life 
Table 1

Somatic symptoms scores and positive somatization tendencies (ST) rates among different baseline characteristics of all subjects $(N=11,153)$.

\begin{tabular}{|c|c|c|c|c|c|c|c|}
\hline Variables & $\begin{array}{c}\text { Total } \\
\mathrm{N}=11,153 \\
\mathrm{n}(\%)\end{array}$ & $\begin{array}{c}\text { Somatic symptoms } \\
\text { scores } \\
\text { Mean } \pm \text { standard } \\
\text { deviation }\end{array}$ & p-value & ST $(n=1,347)$ & $\begin{array}{c}\text { Positive ST rates } \\
\qquad \%(95 \% \mathrm{Cl})\end{array}$ & p-value & OR $(95 \% \mathrm{Cl})$ \\
\hline Overall & $11,153(100.0)$ & $3.94 \pm 1.74$ & NA & 1,347 & $12.1(11.5-12.7)$ & NA & NA \\
\hline \multicolumn{8}{|l|}{ Gender } \\
\hline Female & $5,629(50.5)$ & $4.04 \pm 1.77$ & $<0.001 *$ & 779 & $13.8(12.9-14.8)$ & $<0.001 * *$ & $1.40(1.25-1.58)$ \\
\hline Male & $5,524(49.5)$ & $3.83 \pm 1.71$ & & 568 & $10.3(9.5-11.1)$ & & \\
\hline \multicolumn{8}{|l|}{ Age (years) } \\
\hline 13 & $1,561(14.0)$ & $4.35 \pm 1.98$ & $<0.001 * * *$ & 192 & $12.3(10.7-14.0)$ & $0.006 * *$ & NA \\
\hline 14 & 2,215 (19.9) & $4.01 \pm 1.76$ & & 249 & $11.2(10.0-12.6)$ & & \\
\hline 15 & $1,829(16.4)$ & $4.73 \pm 2.31$ & & 236 & $12.9(11.4-14.5)$ & & \\
\hline 16 & $2,462(22.0)$ & $3.94 \pm 1.62$ & & 261 & $10.6(9.4-11.9)$ & & \\
\hline 17 & $1,836(16.5)$ & $4.30 \pm 1.90$ & & 224 & $12.2(10.7-13.8)$ & & \\
\hline 18 & $1,250(11.2)$ & $4.92 \pm 1.96$ & & 185 & $14.8(12.9-16.9)$ & & \\
\hline \multicolumn{8}{|l|}{ Nationality } \\
\hline Han & $10,972(98.4)$ & $4.34 \pm 1.71$ & 0.274 * & 1,323 & $12.1(11.5-12.7)$ & 0.623 ** & $0.90(0.58-1.45)$ \\
\hline Ethnic minorities & $181(1.6)$ & $5.01 \pm 2.08$ & & 24 & $13.3(8.7-19.1)$ & & \\
\hline \multicolumn{8}{|l|}{ Residence area } \\
\hline Rural & $5,921(53.1)$ & $4.35 \pm 1.94$ & $<0.001$ * & 763 & $12.9(12.0-13.8)$ & $0.005 * *$ & $1.18(1.05-1.32)$ \\
\hline Urban & $5,232(46.9)$ & $3.89 \pm 1.49$ & & 584 & $11.2(10.3-12.0)$ & & \\
\hline \multicolumn{8}{|l|}{$\begin{array}{l}\text { Sampling area } \\
\text { (province) }\end{array}$} \\
\hline Anhui & 3,015 (27.0) & $4.03 \pm 1.52$ & $0.345 * \star *$ & 384 & $12.7(11.6-14.0)$ & $0.385 * *$ & NA \\
\hline Zhejiang & 4,165 (37.4) & $3.98 \pm 1.22$ & & 486 & $11.7(10.7-12.7)$ & & \\
\hline Jiangsu & 3,973 (35.6) & $4.01 \pm 1.65$ & & 477 & $12.0(11.0-13.1)$ & & \\
\hline
\end{tabular}

95\% Cl: 95\% confidence interval; NA: not available; OR: odds ratio.

Note: bold values are those that reached statistical significance $(p<0.05)$.

* Independent t tests;

** Pearson chi-square test;

$\star * *$ Bartlett's one-factor analysis of variance.

adaptation, teacher-student satisfaction, peers' interpersonal interaction and harmony, family expressiveness and organization, family intellectual-cultural orientation, and family activity-recreational orientation) did not significantly relate to ST risk ( $p>0.05)$ (Tables 2 and 3).

To further explore the possible associations between STs and impact factors, a conditional multiple regression analysis was performed, showing that family medical history, HADS-A and HADS-D scores, superstitious beliefs, left-behind adolescents, teacher-student support, family conflict, and family independence and achievement orientation were significantly linked to STs in adolescents (Table 4). The models also indicated that, out of all independent variables, family medical history was the strongest ST impact factor $(\mathrm{amOR}=3.02,95 \% \mathrm{CI}: 1.88-5.76, \mathrm{p}<0.001)$ (Table 4). 
Table 2

Comparison of demographic characteristics between somatization tendencies (ST) and control groups $(n=3,693)$.

\begin{tabular}{|c|c|c|c|c|}
\hline Variables & $\begin{array}{c}\text { ST }(n=1,226) \\
n(\%)\end{array}$ & $\begin{array}{c}\text { Controls }(n=2,467) \\
n(\%)\end{array}$ & p-value * & mOR $(95 \% \mathrm{Cl})$ \\
\hline \multicolumn{5}{|l|}{ Family income } \\
\hline Below middle level & $321(26.2)$ & $526(21.3)$ & 0.001 & $1.30(1.11-1.54)$ \\
\hline Middle level and above & $905(73.8)$ & $1,941(78.7)$ & & \\
\hline \multicolumn{5}{|l|}{ Education level of father } \\
\hline High school and below & 965 (78.7) & $1,879(76.2)$ & 0.083 & $1.16(0.98-1.37)$ \\
\hline College degree and above & $261(21.3)$ & $588(23.8)$ & & \\
\hline \multicolumn{5}{|l|}{ Education level of mother } \\
\hline High school and below & $1,024(83.5)$ & $2,086(84.6)$ & 0.418 & $0.83(0.60-1.17)$ \\
\hline College degree and above & $202(16.5)$ & $381(15.4)$ & & \\
\hline \multicolumn{5}{|l|}{ School administration model } \\
\hline Fully-closed & $315(25.7)$ & $474(19.2)$ & $<0.001$ & NA \\
\hline Semi-closed & $625(51.0)$ & $1,456(59.2)$ & & \\
\hline Open & $286(23.3)$ & $537(21.6)$ & & \\
\hline \multicolumn{5}{|l|}{ Father's occupation } \\
\hline Peasants, no professions & $214(17.5)$ & $459(18.6)$ & 0.394 & $0.93(0.77-1.11)$ \\
\hline Other & $1,012(82.5)$ & $2,008(81.4)$ & & \\
\hline \multicolumn{5}{|l|}{ Mother's occupation } \\
\hline Peasants, no professions & $381(31.1)$ & $752(30.5)$ & 0.712 & $1.03(0.88-1.20)$ \\
\hline Other & 845 (68.9) & $1,715(69.5)$ & & \\
\hline \multicolumn{5}{|l|}{ Recent environment pollution } \\
\hline Yes & $564(46.0)$ & $1,062(43.0)$ & 0.089 & $1.13(0.98-1.30)$ \\
\hline No & $662(54.0)$ & $1,405(57.0)$ & & \\
\hline \multicolumn{5}{|l|}{ Superstitious beliefs in life } \\
\hline Yes & $289(23.6)$ & $442(17.9)$ & $<0.001$ & $1.41(1.19-1.68)$ \\
\hline No & $937(76.4)$ & $2,025(82.1)$ & & \\
\hline \multicolumn{5}{|l|}{ Boarding school } \\
\hline Yes & $261(21.3)$ & $428(17.3)$ & 0.004 & $1.29(1.08-1.54)$ \\
\hline No & $965(78.7)$ & $2,039(82.2)$ & & \\
\hline \multicolumn{5}{|l|}{ Class staff } \\
\hline Yes & $263(21.5)$ & $497(20.1)$ & 0.355 & $1.08(0.91-1.29)$ \\
\hline No & $963(78.5)$ & $1,970(79.9)$ & & \\
\hline \multicolumn{5}{|l|}{ Family medical history } \\
\hline Yes & $78(6.4)$ & $64(2.6)$ & $<0.001$ & $2.55(1.79-3.63)$ \\
\hline No & $1,148(93.6)$ & $2,403(97.4)$ & & \\
\hline \multicolumn{5}{|l|}{ Number of family members } \\
\hline$>5$ & $525(42.8)$ & $989(40.1)$ & 0.112 & $1.12(0.97-1.29)$ \\
\hline$\leq 5$ & $701(57.2)$ & $1,478(59.9)$ & & \\
\hline \multicolumn{5}{|l|}{ Class size } \\
\hline$>45$ & $705(57.5)$ & $1,247(50.5)$ & $<0.001$ & $1.32(1.15-1.52)$ \\
\hline$\leq 45$ & $521(42.5)$ & $1,220(49.5)$ & & \\
\hline \multicolumn{5}{|l|}{ Left-behind adolescents } \\
\hline Yes & 318 (25.9) & $424(17.2)$ & $<0.001$ & $1.69(1.43-2.00)$ \\
\hline No & $908(74.1)$ & $2,043(82.8)$ & & \\
\hline \multicolumn{5}{|l|}{ Somatotype } \\
\hline Ineligible & $785(64.0)$ & $1,489(60.4)$ & 0.031 & $1.17(1.01-1.35)$ \\
\hline Eligible & $441(36.0)$ & 978 (39.6) & & \\
\hline
\end{tabular}

95\%Cl: 95\% confidence interval; mOR: matched odds ratios; NA: not available.

Note: bold values are those that reached statistical significance $(p<0.05)$.

* Pearson chi-square test. 
Table 3

Comparison of environmental factors between somatization tendencies (ST) and control groups $(n=3,693)$.

\begin{tabular}{|c|c|c|c|}
\hline Variables & $\begin{array}{c}\text { ST }(n=1,226) \\
\text { Mean } \pm \text { Standard deviation }\end{array}$ & $\begin{array}{c}\text { Controls }(n=2,467) \\
\text { Mean } \pm \text { standard deviation }\end{array}$ & p-value * \\
\hline \multicolumn{4}{|l|}{ Social adjustment status } \\
\hline Emotional adaptation & $16.6 \pm 4.2$ & $17.1 \pm 3.4$ & $<0.001$ \\
\hline Social adaptation & $15.5 \pm 4.0$ & $15.7 \pm 3.9$ & 0.146 \\
\hline Study and life adaptation & $12.9 \pm 3.6$ & $13.1 \pm 3.4$ & 0.099 \\
\hline \multicolumn{4}{|l|}{ School environment status } \\
\hline \multicolumn{4}{|l|}{ Teacher-student relationship } \\
\hline Intimacy & $17.7 \pm 4.9$ & $18.1 \pm 4.4$ & 0.012 \\
\hline Support & $12.9 \pm 3.5$ & $14.2 \pm 3.3$ & $<0.001$ \\
\hline Satisfaction & $14.4 \pm 3.7$ & $14.6 \pm 3.2$ & 0.096 \\
\hline Conflict & $16.7 \pm 6.2$ & $15.6 \pm 6.5$ & $<0.001$ \\
\hline \multicolumn{4}{|l|}{ Peer relationship } \\
\hline Social emotion & $20.8 \pm 6.1$ & $21.3 \pm 5.8$ & 0.015 \\
\hline Interpersonal interaction & $17.9 \pm 5.9$ & $18.1 \pm 5.3$ & 0.299 \\
\hline Interpersonal harmony & $22.1 \pm 6.7$ & $22.5 \pm 5.9$ & 0.064 \\
\hline \multicolumn{4}{|l|}{ Family environment status } \\
\hline \multicolumn{4}{|l|}{ Relationships dimensions } \\
\hline Cohesion & $5.9 \pm 2.2$ & $6.6 \pm 2.1$ & $<0.001$ \\
\hline Expressiveness & $4.6 \pm 1.9$ & $4.7 \pm 1.5$ & 0.082 \\
\hline Conflict & $3.9 \pm 2.0$ & $2.9 \pm 2.5$ & $<0.001$ \\
\hline \multicolumn{4}{|l|}{ Personal growth dimensions } \\
\hline Independence & $4.6 \pm 1.9$ & $5.3 \pm 1.4$ & $<0.001$ \\
\hline Achievement orientation & $4.9 \pm 1.9$ & $5.8 \pm 1.5$ & $<0.001$ \\
\hline Intellectual-cultural orientation & $4.1 \pm 2.1$ & $4.2 \pm 1.6$ & 0.108 \\
\hline Active-recreational orientation & $4.4 \pm 2.2$ & $4.5 \pm 1.9$ & 0.154 \\
\hline Moral-religious emphasis & $5.0 \pm 1.7$ & $5.7 \pm 1.2$ & $<0.001$ \\
\hline \multicolumn{4}{|l|}{ System maintenance dimensions } \\
\hline Organization & $6.2 \pm 1.7$ & $6.1 \pm 1.5$ & 0.068 \\
\hline Control & $3.9 \pm 2.0$ & $4.6 \pm 1.5$ & $<0.001$ \\
\hline HADS-A score & $6.1 \pm 2.1$ & $3.7 \pm 1.8$ & $<0.001$ \\
\hline HADS-D score & $4.5 \pm 1.7$ & $3.4 \pm 2.2$ & $<0.001$ \\
\hline
\end{tabular}

HADS: Hospital Anxiety and Depression Scale; HADS-A: HADS-anxiety; HADS-D: HADS-depression.

Note: bold values are those that reached statistical significance $(p<0.05)$.

* Independent $t$ tests.

\section{Discussion}

\section{The prevalence of ST and SSS in adolescents}

This is the first study to investigate and prove the prevalence of STs within a large sample of Chinese adolescents. Adolescent STs may become a serious public health problem in East China. Kihlstrom et al. 33 report that the prevalence of dissociative tendencies in adolescents lies between 10\% and 19\%; results similar to those of our study. Other results have likewise been found in some studies with depressive and anxiety tendencies 34,35 . Our results indicate that, for preventing SD, STs and other mental disorders in adolescents, intervention strategies should be implemented.

As reported in our study, differences of adolescent gender, age, and dwelling area emerged in the SSS and positive ST rate of teenagers. Adolescent ST seems to affect more females than males, and a 
Table 4

Analysis of conditional multiple logistic regression of somatization tendencies (ST) on ST-associated impact factors.

\begin{tabular}{|c|c|c|c|c|c|}
\hline Variables & Coefficient & Standard error (coefficient) & Wald & p-value & amOR $(95 \% \mathrm{Cl})$ \\
\hline \multicolumn{6}{|l|}{ Demographic characteristics } \\
\hline Family income & 0.1997 & 0.1301 & 1.58 & 0.087 & $1.29(0.91-1.59)$ \\
\hline School administration model & 0.1564 & 0.1061 & 1.81 & 0.065 & $1.18(0.99-1.58)$ \\
\hline Boarding school & 0.1072 & 0.0873 & 1.23 & 0.107 & $1.14(0.83-1.56)$ \\
\hline Superstitious beliefs in life & 0.3108 & 0.1407 & 2.53 & 0.011 & $1.46(1.05-1.89)$ \\
\hline Family medical history & 0.7023 & 0.3258 & 6.52 & $<0.001$ & $3.02(1.88-5.76)$ \\
\hline Class size & 0.2125 & 0.0952 & 1.16 & 0.114 & $1.31(0.92-1.96)$ \\
\hline Left-behind adolescents & 0.2345 & 0.1752 & 2.49 & 0.014 & $1.32(1.12-1.94)$ \\
\hline Somatotype & 0.2032 & 0.0893 & 1.16 & 0.103 & $1.27(0.92-1.55)$ \\
\hline \multicolumn{6}{|l|}{ Social adjustment status } \\
\hline Emotional adaptation & 0.0221 & 0.0164 & 0.81 & 0.412 & $0.99(0.94-1.16)$ \\
\hline \multicolumn{6}{|l|}{ School environment status } \\
\hline \multicolumn{6}{|l|}{ Teacher-student relationship } \\
\hline Intimacy & 0.0358 & 0.0237 & 1.06 & 0.174 & $1.06(0.94-1.14)$ \\
\hline Support & -0.1145 & 0.1089 & -2.27 & 0.022 & $0.82(0.77-0.96)$ \\
\hline Conflict & 0.1670 & 0.1194 & 1.81 & 0.062 & $1.31(0.98-1.48)$ \\
\hline \multicolumn{6}{|l|}{ Peer relationship } \\
\hline Social emotion & 0.0085 & 0.0105 & 0.32 & 0.641 & $0.99(0.78-1.02)$ \\
\hline \multicolumn{6}{|l|}{ Family environment status } \\
\hline \multicolumn{6}{|l|}{ Relationships dimensions } \\
\hline Cohesion & -0.0754 & 0.0448 & -1.88 & 0.058 & $0.96(0.89-1.12)$ \\
\hline Conflict & 0.2891 & 0.1309 & 2.97 & 0.003 & $1.38(1.03-1.64)$ \\
\hline \multicolumn{6}{|l|}{ Personal growth dimensions } \\
\hline Independence & -0.1365 & 0.0533 & -3.81 & $<0.001$ & $0.85(0.72-0.94)$ \\
\hline Achievement orientation & -0.2109 & 0.0496 & -3.88 & $<0.001$ & $0.77(0.61-0.90)$ \\
\hline Moral-religious emphasis & -0.0321 & 0.0481 & -0.94 & 0.227 & $0.97(0.91-1.05)$ \\
\hline \multicolumn{6}{|l|}{ System maintenance dimensions } \\
\hline Control & 0.1616 & 0.1171 & 1.26 & 0.101 & $1.08(0.96-1.17)$ \\
\hline HADS-D score & 0.3551 & 0.1987 & 3.69 & $<0.001$ & $1.84(1.27-2.86)$ \\
\hline HADS-A score & 0.4252 & 0.2149 & 3.71 & $<0.001$ & $2.11(1.59-2.96)$ \\
\hline
\end{tabular}

95\%Cl: 95\% confidence intervals; amOR: adjusted matched odds ratios; HADS: Hospital Anxiety and Depression Scale; HADS-A: HADS-anxiety; HADS-D: HADS-depression.

Note: the parameter estimates for each demographic characteristic, social adjustment status, school and family environment factors were controlled by age, gender, and residence area. Bold values are those that reached statistical significance $(p<0.05)$.

similar phenomenon appears in SD rates 36 . The reason for such gender discrepancy might be related to differences in emotional development during adolescence. We found the SSS and positive ST rate in adolescents aged 18 years old (grade 3 senior high school students) were significantly higher than in other age groups. In addition, the SSS of grade 3 junior high school students is higher than grades 1 or 2. Compas et al. 37 suggest that successful adaptation to stress includes the ways in which individuals manage their emotions and think constructively, as well as how they act in social and nonsocial environments so as to alter or decrease stress levels. In contrast, failed adaptation to stress probably results in psychological problems. However, some adolescents aged 15-18 years most likely cannot effectively decrease sources of severe stress featured in this study. Thus, the prevalence of STs is higher in this population.

Another reason for the high prevalence of STs might be that there is a serious shortage of mental health education in schools. Evidence exists that, compared with adolescents at other levels of 
urbanization, rural adolescents fare worse on many indicators of mental health 38 . Our study also found that adolescents in rural areas had significantly higher SSS and ST prevalence than in urban areas. As before, we suggest sex-specific, age-specific, and area-specific intervention programs should be considered to prevent STs in adolescents.

\section{The environmental impact factors of adolescent STs}

To our best knowledge, this is the first study to examine the associations between adolescent STs and a broad range of potential impact factors using a large population sample. In this study, family medical history, HADS-A and HADS-D scores, superstitious beliefs, left-behind adolescents, teacher-student support, family conflict, and family independence and achievement orientation contributed to the STs impact. It is worth noting that family medical history, HADS-A and HADS-D scores, superstitious beliefs, and family conflicts are significantly associated with STs. Our study implicates that bio-genetic, psychological, and family factors are the key impact factors in adolescents with STs. As reported in a recent study, possible genetic and environmental factors contribute to somatic symptoms in children and adolescents 39 ; a result which appears to be consistent with our study. Previous studies also state an association between SD and depression or anxiety disorders 7. Similarly, exposure to depressive or anxiety symptoms was a risk factor for adolescent STs in our study. Why are depression and anxiety patients more likely to suffer from STs in adolescence? Such results may be due to the fact these patients likely experience more medical testing, days away from home and school, and also family financial burden compared with mentally healthy adolescents who are still in school. Moreover, previous work with patient samples highlights that frequent and recurrent somatic symptoms in children predict a substantially increased risk for emotional distress disorders (such as depression and anxiety) during young adulthood 7 . Therefore, the relationship between SD and depression or anxiety disorders are that of a psychiatric comorbidity.

Studies confirm that religious beliefs were found to significantly impact mental health 5 . For instance, negative approaches to superstitious beliefs appear to be positively associated with anxiety disorders, as reported by James \& Wells 40 . This study shows that a significant association is found between STs and superstitious beliefs and, therefore, the existence of superstitious beliefs among adolescents should be emphasized as a high-risk ST indicator. As a result, Education and mental health professionals should observe high-risk adolescents with superstitious beliefs.

Our findings also indicate that left-behind adolescents are associated with STs. Parental migration may result in left-behind adolescents who are raised by other family members, such as grandparents 41 . Any subsequent differences between parents and other caretakers in terms of family roles, education levels, and lifestyles may contribute to an unfavorable environment for the adolescents' psychological development 41 .

In our study, teacher-student support is associated with a decreased risk of adolescent STs. Teacher support may be especially important for student engagement in school when adolescents are coping with stressful life events and their independent coping skills are developing 42 . A secure relationship with a teacher may serve as a resource that permits young students to cope more effectively with novel academic and social demands. For example, Wang et al. 43 report that, among adolescents, emotional security with a teacher attenuates stress reactivity to negative events in the classroom. Other studies also show that the quality of teacher-student relationships in school has implications for the adolescents' future academic, social, and behavioral outcomes 41 .

We found that interpersonal relationships in families of ST adolescents are characterized by more conflicts and less independence in comparison with families of non-ST adolescents; a negative family climate, for instance, may also affect the maintenance of mental disorders 44 . This is most likely due to the complex and reciprocal influences of the overall family environment on the mental health development of adolescents. Conversely, a positive family climate may provide a "safe haven" for high-risk adolescents, support healthy development and optimal learning and living, and discourage the maladaptive behavior. Sheeber et al. 45 assert that a stable family circumstance can play a key role in promoting the psychological health of adolescents. A related study suggests that family conflict has unique and direct associations with the emotional health of adolescents 46 . It is well known that favorable family growth environments are conducive to adolescent mental health; hence, this study 
suggests that family achievement orientation is helpful in reducing adolescent STs. Given our and others' studies, we believe mental therapies and family interventions are key to addressing the high ST prevalence among adolescents.

Most notably, our study suggests that family medical history is the strongest impact factor of adolescent STs. Early data found a highly significant association between family medical history and somatoform symptoms in children and adolescents 47; the World Health Organization also proved that each parent disorder examined, with the exception of suicide, was associated with an increased risk of offspring mental disorders 48 . Both of these sources are consistent with our findings.

Although the causes of both SD and STs are not very clear, the genetic transmission of mental disorders (meaning family medical history as an independent ST impact factor) is a likely mechanism. Whatever the pathogenesis of STs may be, a word of caution is justified given their adverse outcomes. As such, we suggest that early diagnosis and treatment of mental disorders in family members may effectively reduce the risk of adolescent STs and disease burdens, as well as supportive intervention for existing STs.

\section{Limitations}

Several limitations of this study shall be considered. Firstly, some of the data in our study were self-reported and, possibly, underreported; however, the confidential nature of our questionnaire may have significantly decreased underreporting. Second, because there is no standard approach for measuring STs, misclassification of some outcomes may have resulted in the underestimation of the associations between STs and impact factors; such underestimation may have been reduced by integrating both subjective and objective methods to measure ST. Additionally, only adolescents attending school were sampled; out-of-school adolescents were not included in this study. Thus, some caution should be exercised when generalizing the results from this study population to the entire adolescent population in China.

\section{Contributors}

Q. Cheng designed the study, conducted the statistical analyses and wrote the first draft of the manuscript. Y. Xu designed the study and revised the manuscript. L. Xie conducted the statistical analyses and wrote the first draft of the manuscript. Y. Hu and Y. Lv carried out the field research and revised the manuscript.

\section{Additional informations}

ORCID: Qinglin Cheng (0000-0003-2899-7626); Yong Xu (0000-0002-9755-1102); Li Xie (00000003-3368-4747); Yunkai Hu (0000-0002-48059496); Yongxiang Lv (0000-0001-9373-641X).

\section{Acknowledgments}

We would like to thank the participants and their guardians for kindly participating in this study, and the staff members of three School Health Surveillance System (SHSS) centers for their assistance in the field investigation for adolescents' STs. This study was funded by the National Health and Family Planning Commission of the People's Republic of China (grant n. 201202010) and Health and Family Planning Commission of Hangzhou Municipality (grant n. 2012A060). 


\section{References}

1. Lipowski ZJ. Somatization: medicine's unsolved problem. Psychosomatics 1987; 28:294-7.

2. Lipowski ZJ. Somatization: the concept and its clinical application. Am J Psychiatry 1988; 145:1358-68.

3. Silber TJ, Pao M. Somatization disorders in children and adolescents. Pediatr Rev 2003; 24:255-61.

4. Ruchkin V, Schwab-Stone M. A longitudinal study of somatic complaints in urban adolescents: the role of internalizing psychopathology and somatic anxiety. J Youth Adolesc 2014; 43:834-45.

5. Silber TJ. Somatization disorders. Pediatr Rev 2011; 32:56-64.

6. Faravelli C, Salvatori S, Galassi F, Aiazzi L, Drei C, Cabras P. Epidemiology of somatoform disorders: a community survey in Florence. Soc Psychiatry Psychiatr Epidemiol 1997; 32:24-9.

7. Lieb R, Pfister H, Mastaler M, Wittchen HU. Somatoform syndromes and disorders in a representative population sample of adolescents and young adults: prevalence, comorbidity and impairments. Acta Psychiatr Scand 2000; 101:194-208.

8. Viernes N, Zaidan ZA, Dorvlo AS, Kayano M, Yoishiuchi K, Kumano H, et al. Tendency toward deliberate food restriction, fear of fatness and somatic attribution in cross-cultural samples. Eat Behav 2007; 8:407-17.

9. Kroenke K, Outcalt S, Krebs E, Bair MJ, Wu J, Chumbler N, et al. Association between anxiety, health-related quality of life and functional impairment in primary care patients with chronic pain. Gen Hosp Psychiatry 2013; 35:359-65.

10. Costello EJ, Egger H, Angold A. 10-year research update review: the epidemiology of child and adolescent psychiatric disorders: I. Methods and public health burden. J Am Acad Child Adolesc Psychiatry 2005; 44:972-86.

11. Gardner RM, Morrell Jr. JA, Ostrowski TA. Somatization tendencies and ability to detect internal body cues. Percept Mot Skills 1990; 71:364-6.

12. Zhou X, Min S, Sun J, Kim SJ, Ahn JS, Peng $\mathrm{Y}$, et al. Extending a structural model of somatization to South Koreans: cultural values, somatization tendency, and the presentation of depressive symptoms. J Affect Disord 2015; 176:151-4.

13. Vargas-Prada S, Martínez JM, Coggon D, Delclos G, Benavides FG, Serra C. Health beliefs, low mood, and somatizing tendency: contribution to incidence and persistence of musculoskeletal pain with and without reported disability. Scand J Work Environ Health 2013; 39:589-98.
14. McCall-Hosenfeld JS, Winter M, Heeren T, Liebschutz JM. The association of interpersonal trauma with somatic symptom severity in a primary care population with chronic pain: exploring the role of gender and the mental health sequelae of trauma. J Psychosom Res 2014; 77:196-204.

15. Yoo SK. The cultural impact on depression expression and attitudes toward seeking professional help: a comparative study of Americans and South Koreans. Asia Pacific Education Review 2001; 2:94-100.

16. Daniel WW. Biostatistics: a foundation for analysis in the health sciences. 7th Ed. New York: John Wiley \& Sons; 1999.

17. Derogatis LR, Melisaratos N. The Brief Symptom Inventory: an introductory report. Psychol Med 1983; 13:595-605.

18. Clason DL, Dormody TJ. Analyzing data measured by individual Likert-type items. J Agric Educ 1994; 35:31-5.

19. Villanueva Badenes L, Prado-Gascó V, González Barrón R. Emotion awareness, mood and personality as predictors of somatic complaints in children and adults. Psicothema 2016; 28:383-8.

20. Zijlema WL, Morley DW, Stolk RP, Rosmalen JG. Noise and somatic symptoms: a role for personality traits? Int J Hyg Environ Health 2015; 218:543-9.

21. De Gucht V, Fischler B, Heiser W. Job stress, personality, and psychological distress as determinants of somatization and functional somatic syndromes in a population of nurses. Stress Health 2003; 19:195-204.

22. Gong Y. The manual of Wechsler adult intelligence scale revised in China. Changsha: $\mathrm{Hu}-$ nan Medical University Press; 1992.

23. Breslau N, Paneth N, Lucia VC, Paneth-Pollak R. Maternal smoking during pregnancy and offspring IQ. Int J Epidemiol 2005; 34: 1047-53.

24. Zhang YB. The current situation and relationship of self-cognition, self-evaluation and adaptation of Chinese junior high school students. Beijing: Tsinghua University; 2008.

25. Zhang DJ, Jiang Q. A report on construction of adaptation scale for adolescent. Studies of Psychology and Behavior 2006; 4:81-4.

26. Pianta RC. The student-teacher relationship scale. Charlottesville: University of Virginia; 2001.

27. Qu ZY. The characteristics of class environment and its relationship with students' school adjustment in primary and middle school. Beijing: Beijing Normal University; 2002.

28. Wei YH. A study on structure model and factors influencing the self-esteem development in children and adolescents. Beijing: Beijing Normal University; 1997. 
29. Borduin CM, Blaske DM, Cone L, Mann BJ, Hazelrigg M. Development and validation of a measure of adolescent peer relations: the Missouri Peer Relations Inventory. Columbia: Department of Psychological Sciences, University of Missouri; 1989.

30. Phillips MR, West CL, Shen Q, Zheng Y. Comparison of schizophrenic patients' families and normal families in China, using Chinese versions of FACES-II and the family environment scales. Fam Process 1998; 37:95-106.

31. Hong JS, Tian J. Prevalence of anxiety and depression and their risk factors in Chinese cancer patients. Support Care Cancer 2014; 22:453-9.

32. Bjelland I, Dahl AA, Haug TT, Neckelmann D. The validity of the Hospital Anxiety and Depression Scale: an updated literature review. J Psychosom Res 2002; 52:69-77.

33. Kihlstrom JF, Glisky ML, Angiulo MJ. Dissociative tendencies and dissociative disorders. J Abnorm Psychol 1994; 103:117-24.

34. Saluja G, Iachan R, Scheidt PC, Overpeck MD, Sun W, Giedd JN. Prevalence of and risk factors for depressive symptoms among young adolescents. Arch Pediatr Adolesc Med 2004; 158:760-5.

35. Lewinsohn PM, Gotlib IH, Lewinsohn M, Seeley JR, Allen NB. Gender differences in anxiety disorders and anxiety symptoms in adolescents. J Abnorm Psychol 1998; 107:109-17.

36. Milani RM, Parrott AC, Turner JJ, Fox HC. Gender differences in self-reported anxiety, depression, and somatization among ecstasy/ MDMA polydrug users, alcohol/tobacco users, and nondrug users. Addict Behav 2004; 29:965-71.

37. Compas BE, Connor-Smith JK, Saltzman H, Thomsen AH, Wadsworth ME. Coping with stress during childhood and adolescence: problems, progress, and potential in theory and research. Psychol Bull 2001; 127:87-127.

38. Srinath S, Girimaji SC, Gururaj G, Seshadri S, Subbakrishna DK, Bhola P, et al. Epidemiological study of child \& adolescent psychiatric disorders in urban \& rural areas of Bangalore, India. Indian J Med Res 2005; 122:67-79.
39. Tøt-Strate S, Dehlholm-Lambertsen G, Lassen $\mathrm{K}$, Rask CU. Clinical features of functional somatic symptoms in children and referral patterns to child and adolescent mental health services. Acta Paediatr 2016; 105:514-21.

40. James A, Wells A. Death beliefs, superstitious beliefs and health anxiety. Br J Clin Psychol 2002; 41:43-53.

41. Zhang N, Bécares L, Chandola T. Does the timing of parental migration matter for child growth? A life course study on left-behind children in rural China. BMC Public Health 2015; 15:966.

42. Reddy R, Rhodes JE, Mulhall P. The influence of teacher support on student adjustment in the middle school years: a latent growth curve study. Dev Psychopathol 2003; 15:119-38.

43. Wang MT, Brinkworth M, Eccles J. Moderating effects of teacher-student relationship in adolescent trajectories of emotional and behavioral adjustment. Dev Psychol 2013; 49:690-705.

44. Peris TS, Sugar CA, Bergman RL, Chang S, Langley A, Piacentini J. Family factors predict treatment outcome for pediatric obsessivecompulsive disorder. J Consult Clin Psychol 2012; 80:255-63.

45. Sheeber L, Hops H, Alpert A, Davis B, Andrews J. Family support and conflict: prospective relations to adolescent depression. J Abnorm Child Psychol 1997; 25:333-44.

46. Timmons AC, Margolin G. Family conflict, mood, and adolescents' daily school problems: Moderating roles of internalizing and externalizing symptoms. Child Dev 2015; 86: 241-58.

47. Schulte IE, Petermann F. Familial risk factors for the development of somatoform symptoms and disorders in children and adolescents: a systematic review. Child Psychiatry Hum Dev 2011; 42:569-83.

48. McLaughlin KA, Gadermann AM, Hwang I, Sampson NA, Al-Hamzawi A, Andrade LH, et al. Parent psychopathology and offspring mental disorders: results from the WHO World Mental Health Surveys. Br J Psychiatry 2012; 200:290-9. 


\section{Resumo}

O objetivo deste estudo é examinar a prevalência e fatores de impacto de tendências de somatização (TS) em adolescentes em três províncias do leste da China. Um estudo transversal multicêntrico baseado em escolas foi realizado nessas províncias de 2015 a 2016. A amostra incluiu 11.153 estudantes entre 13 e 18 anos que foram selecionados aleatoriamente usando uma técnica de amostragem estratificada por clusters multi-fase. Também elaboramos um estudo caso-controle multicêntrico baseado em escolas para avaliar o impacto ambiental potencial de fatores de TS nessa população. A taxa positiva geral de TS entre adolescentes do leste chinês foi de 12,1\%. O escore de sintomas somáticos (SSS) e taxa positiva de TS foram mais altos entre mulheres do que homens. Adicionalmente, o SSS e taxa positiva de TS para o grupo de 18 anos foram significativamente mais altos do que em outros grupos etários. Em comparação com os habitantes de áreas urbanas, adolescentes de áreas rurais tiveram SSS e taxa positiva de ST significativamente mais altos. Análises de regressão múltipla condicional revelaram que o histórico de saúde da família; scores de ansiedade e depressão; crenças supersticiosas; adolescentes deixados para trás; apoio de professores a estudantes; conflito familiar; e independência familiar e orientação para sucesso estavam significativamente relacionadas a TS em adolescentes. O modelo também indicou que o histórico de saúde da família era o fator de impacto mais forte para TS em adolescentes, ainda que TS sejam prevalentes nas três províncias do leste da China estudadas. Gênero, idade e diferenças residenciais foram muito significativos para o SSS e taxa positiva de TS entre adolescentes. Este estudo conclui que TS entre adolescentes são influenciadas por múltiplos ambientes.

Transtornos Somatoformes; Adolescente; Prevalência; Estudo Multicêntrico

\section{Resumen}

El objetivo de este estudio fue examinar la prevalencia y factores de impacto de las tendencias de somatización adolescentes (TS) en tres provincias orientales chinas. Se realizó un estudio trasversal multicéntrico, basado en escolares de estas provincias de 2015 a 2016. La muestra incluyó a 11.153 estudiantes de secundaria, con edades comprendidas entre los 13-18 años, que fueron seleccionados aleatoriamente, usando a técnicas de muestreo multifase estratificado por conglomerados. También se diseñó un estudio multicéntrico escolar de caso-control para evaluar el potencial impacto ambiental de factores TS en esta población. La tasa positiva general de TS entre adolescentes chinos orientales fue un 12,1\%. El marcador de sintomas somáticos (SSS, por sus siglas en inglés) y tasa positiva de TS fueron más altos en mujeres que en hombres. Asimismo, las tasas SSS y TS positiva para el grupo de 18 años de edad fueron significativamente más altas que en otros grupos de edad. En comparación con quienes vivían en áreas urbanas, los adolescentes en áreas rurales contaban con tasas significativamente más altas de SSS y TS positivas. Los análisis de regresión múltiple condicional revelaron que el historial médico familiar, los marcadores de ansiedad y depresión; creencias supersticiosas; adolescentes a la zaga respecto al resto del grupo; el apoyo profesor-estudiante; conflictos familiares; e independencia familiar, así como la orientación de logros estuvieron vinculados a las TS en adolescentes. Los modelos también indicaron que el historial médico familiar fue el impacto más fuerte para las TS en adolescentes, a pesar de que las TS fueron prevalentes en las tres provincias chinas estudiadas. El género, edad, y las diferencias de vivienda fueron muy significativas en la tasas de SSS y TS positivas en adolescentes. Este estudio llega a la conclusión de que las TS adolescentes estaban influenciadas por múltiples entornos.

Trastornos Somatomorfos; Adolescente;

Prevalencia; Estudio Muticéntrico
Submitted on $17 / \mathrm{Jan} / 2018$

Final version resubmitted on 03/Aug/2018

Approved on 17/Aug/2018 